\title{
Microrganismos degradadores de petróleo isolados de solos rizosféricos da Província Petrolífera de Urucu, Coari, Amazonas
}

As atividades relacionadas à exploração do petróleo vêm trazendo grande preocupação devido aos riscos de derrames acidentais. Na Província Petrolífera de Urucu vem sendo realizada atividades de exploração e produção de petróleo e gás natural desde 1986. O petróleo de Urucu é transportado dos poços para a planta central através de um oleoduto construído em 1997. Ao longo do tempo o oleoduto pode apresentar desgaste, podendo ocorrer vazamentos e possíveis contaminações no ambiente. $\mathrm{O}$ objetivo desta pesquisa foi determinar a existência de microrganismos do solo na rizosfera de plantas ao redor de oleoduto com potencialidade para degradar o petróleo de Urucu caso ocorra algum derramamento. Foram realizadas quatro coletas de campo em duas épocas diferentes, sendo obtidos solos rizosféricos de duas espécies de gramíneas (Brachiaria humidicola, Brachiaria decumbens), uma leguminosa (Mucuna pruriens) e um lacre (Vismia guianensis). A adição de petróleo ao meio de cultura resultou em aumentos significativos de microrganismos capazes de degradar esse complexo orgânico, com as populações de bactérias ultrapassando 4,5x108 UFC.g-1 de solo, fungos filamentosos ultrapassando 1,4x107 UFC.g-1 de solo e leveduras ultrapassando 6,0x107 UFC.g-1 de solo, populações essas, capazes de contribuir para a degradação do petróleo caso ocorra algum derramamento ao longo do oleoduto. Entre as quatro espécies, a Brachiaria decumbens apresentou a maior ocorrência de microrganismos degradadores de petróleo. As maiores concentrações de UFC (Unidades Formadoras de Colônias) de bactérias, fungos filamentosos e leveduras ocorreram no período seco. No período chuvoso, a maior concentração de UFC de bactérias ocorreu em Brachiaria humidicola e, de fungos filamentosos e leveduras em Mucuna prurinens. No período seco, a maior concentração de UFC de bactérias ocorreu em Brachiaria decumbens, de fungos filamentosos em Mucuna pruriens e leveduras em Brachiaria decumbens.

\section{Petroleum degrading microorganisms isolated from rhizospheric soils in the Urucu Petroleum Province, Coari, Amazonas}

Activities related to oil exploration have been of great concern due to the risk of accidental spills. In the Petroleum Province of Urucu, oil and natural gas exploration and production activities have been carried out since 1986. Urucu oil is transported from the wells to the central plant through an oil pipeline built in 1997. Ove time, the oil pipeline may wear out, leaks and possible contamination in the environment may occur. The objective of this research was to determine the existence of soil microorganisms in the rhizosphere of plants around the pipeline with the potential to degrade Urucu oil in the event of a spill. Four field samples were taken at two different times, with rhizospheric soils from two species of grasses (Brachiaria humidicola, Brachiaria decumbens), a legume (Mucuna pruriens) and a vismia (Vismia guianensis). The addition of oil to the culture medium resulted in significant increases in microorganisms capable of degrading this organic complex, with bacterial populations exceeding 4.5x108 CFU.g-1 of soil, filamentous fungi exceeding 1.4 x107 CFU.g-1 of soil and yeasts exceeding $6.0 \times 107$ CFU.g-1 of soil. These populations can contribute to the degradation of oil in the event of a spill along the pipeline. Among the four species, Brachiaria decumbens had the highest occurrence of petroleum degrading microorganisms. The highest concentrations of CFU (Colony Forming Units) of bacteria, filamentous fungi and yeasts occurred in the dry period. In the rainy season, the highest CFU concentration of bacteria occurred in Brachiaria humidicola, and of filamentous fungi and yeast in Mucuna prurinens. In the dry season, the highest CFU concentration of bacteria occurred in Brachiaria decumbens, of filamentous fungi in Mucuna pruriens and yeasts in Brachiaria decumbens.

Keywords: Biodegradation; Soil Contamination; Microorganisms; Petroleum.

Topic: Microbiologia Agrícola e Ambiental

Reviewed anonymously in the process of blind peer.

Dannielle Cordeiro Ribeiro de Lima (iD)

Universidade Nilton Lins, Brasil

http://lattes.cnpq.br/2954789516390909

http://orcid.org/0000-0002-1642-3230

dannielle.cordeiro@gmail.com

Francisco Wesen Moreira (iD

Instituto Nacional de Pesquisas da Amazônia, Brasil

http://lattes.cnpq.br/1416538021119110

http://orcid.org/0000-0002-8763-254X

wesen@inpa.gov.br

Cassiane Minelli Oliveira

Universidade Paulista, Brasil

http://lattes.cnpq.br/3681043451620632

http://orcid.org/0000-0003-4827-9955

cassyminelli@hotmail.com

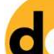

DOI: 10.6008/CBPC2179-6858.2020.003.0007
Received: $13 / 03 / 2020$

Approved: 19/04/2020

\author{
Luiz Antonio de Oliveira \\ Instituto Nacional de Pesquisas da Amazônia, Brasil \\ http://lattes.cnpq.br/9931395111001102 \\ http://orcid.org/0000-0002-2008-7292 \\ luiz.oliveira@inpa.gov.br
}

Referencing this:

LIMA, D. C. R.; MOREIRA, F. W.; OLIVEIRA, C. M.; OLIVEIRA, L. A. Microrganismos degradadores de petróleo isolados de solos rizosféricos da Província Petrolífera de Urucu, Coari, Amazonas. Revista Ibero Americana de Ciências Ambientais, v.11, n.3, p.66-78, 2020. DOI: http://doi.org/10.6008/CBPC2179-6858.2020.003.0007 


\section{INTRODUÇÃO}

Na Província Petrolífera de Urucu, localizada no município de Coari, Amazonas, vêm sendo realizadas atividades de exploração e produção de petróleo e gás natural desde 1986 pela Petrobras S.A. O petróleo de Urucu é transportado dos poços para a planta central (Polo Arara) através de oleodutos construídos em 1997. Para facilitar os trabalhos de manutenção desses dutos, a Petrobras mantém uma faixa ao longo desses dutos com uma vegetação rasteira, composta de gramíneas como duas espécies de braquiária (Brachiaria humidicola, Brachiaria decumbens), uma leguminosa de ocorrência esporádica (Mucuna pruriens) e o lacre (Vismia guianensis), sendo este, um componente de plantas invasoras pioneiras que ocorrem espontaneamente na região.

Ao longo do tempo, o oleoduto pode apresentar desgaste, podendo ocorrer vazamentos e contaminações no ambiente. No sistema radicular das plantas ocorre uma diversidade elevada de microrganismos, principalmente bactérias, que usam os exsudatos radiculares para crescerem e colonizarem as raízes. Esses microrganismos, classificados genericamente de 'rizosféricos', apresentam metabolismo capaz de usar diferentes fontes de carbono, podendo, inclusive, serem usados para a biorremediação de ambientes contaminados com xenobióticos (MURATOVA et al., 2003). Plantas que mantêm altas populações de microrganismos degradadores de petróleo são desejáveis ao longo desses oleodutos, como forma de prevenção para o caso de ocorrer futuros vazamentos.

Não há pesquisas voltadas para a identificação e quantificação da presença desses microrganismos nas rizosferas das quatro espécies, como forma de validar ou não a contribuição de suas rizosferas para possíveis tratamentos de derramamentos de petróleo ao longo do oleoduto. Desse modo, a presente pesquisa teve como objetivo, verificar a existência de microrganismos do solo na rizosfera das quatro espécies de plantas ao redor do oleoduto com potencialidade de degradar o petróleo e saber em qual solo rizosférico coletado há maior ocorrência de microrganismos degradadores de petróleo em dois períodos climáticos (seco e chuvoso).

\section{MATERIAIS E MÉTODOS}

O estudo foi realizado na Província Petrolífera de Urucu, situada no município de Coari, no estado do Amazonas, às margens do Rio Urucu, distante cerca de $650 \mathrm{~km}$ em linha reta de Manaus. O clima é classificado como tropical úmido, de acordo com a classificação de Köppen. A umidade relativa do ar é bastante elevada em toda a região, em torno de $80 \%$. A tipologia florestal dominante é a Floresta Pluvial Tropical Densa de Terra Firme. Apresenta chuvas relativamente abundantes durante todo o ano (média de $2.250 \mathrm{~mm}$ ), sendo que a precipitação no mês em que menos chove é sempre superior a $60 \mathrm{~mm}$. A temperatura média anual da região é de aproximadamente $26^{\circ} \mathrm{C}$ (VIEIRA et al., 1987).

Para o presente estudo foram realizadas quatro coletas nos Campos de RUC e LUC. As coletas foram baseadas no ciclo hidrológico da região, sendo duas na época chuvosa (29/01/2009 e 19/06/2009) e duas na época de seca (24/09/2009 e 25/11/2009), sendo obtidas de plantas ao redor do oleoduto. Solos rizosféricos 
de duas espécies de gramíneas (Brachiaria humidicola, Brachiaria decumbens), uma leguminosa (Mucuna pruriens) e um lacre (Vismia guianensis) foram coletados até $20 \mathrm{~cm}$ de profundidade. Após as coletas, as amostras foram acondicionadas em sacos plásticos de polietileno em caixas de isopor com gelo seco à temperatura de $2-4{ }^{\circ} \mathrm{C}$ (ANDERSON et al., 1993).

As análises físico-químicas dos solos foram realizadas no Laboratório Temático de Análise de Plantas e Solo do Instituto Nacional de Pesquisas da Amazônia (INPA) conforme recomendado pelo Manual de Análises Químicas de Solos, Plantas e Fertilizantes (EMBRAPA, 2009).

O enriquecimento das amostras foi realizado no Laboratório de Ecologia e Biotecnologia de Microrganismos da Amazônia do INPA (LEBMAM), onde foi dimensionada a população de microrganismos nos solos rizosféricos das quatro espécies capazes de degradar o petróleo. Os ensaios enriquecidos foram divididos em tratamentos (solos rizosféricos das quatro espécies citadas), com triplicata. Cada amostra foi submetida a dois tratamentos diferentes: ausência de petróleo (testemunha) e adição de petróleo. As amostras de solo rizosférico $(5 \mathrm{~g})$ foram adicionadas em erlenmeyers de $125 \mathrm{~mL}$, contendo $50 \mathrm{~mL}$ de Meio Mineral Bushnell Haas - BH (ATLAS, 1995) modificado, substituindo 1,0g de $\mathrm{NH}_{4} \mathrm{NO}_{3}$ por $1,65 \mathrm{~g}$ de $(\mathrm{NH} 4) 2 \mathrm{SO}_{4}$, com ou sem (testemunha) a adição de $0,5 \mathrm{~mL}$ do petróleo de Urucu como fonte de carbono. Com esse procedimento, os microrganismos capazes de degradar o petróleo apresentaram maiores populações do que nas amostras de solo sem a adição desse produto químico (testemunha), onde os microrganismos usaram apenas a matéria orgânica dos solos como fonte de carbono. Os tratamentos foram colocados em mesa agitadora $(125 \mathrm{rpm})$ à temperatura de $30^{\circ} \mathrm{C} \pm 1^{\circ} \mathrm{C}$. Nas primeiras horas (dia 0 ) foi realizada diluição seriada para estimar a população dos microrganismos que apresentaram crescimento na presença de petróleo. 0 mesmo procedimento foi realizado a cada 7 dias.

Para a contagem dos microrganismos capazes de degradar o petróleo presentes nas amostras de solos, foi realizada diluição seriada usando água destilada esterilizada, colocando cada diluição em Placas de Petri contendo meio de cultura BH sólido (15g de agar por litro), usando petróleo como fonte de carbono $(0,1 \mathrm{~mL}$ por placa), com três repetições para cada diluição. Esse processo foi feito com as testemunhas (suspensão do solo sem petróleo) e com os tratamentos enriquecidos com petróleo. Em seguida, as placas foram incubadas à temperatura ambiente de $30^{\circ} \mathrm{C} \pm 1^{\circ} \mathrm{C}$ por um período de 48 a 72 horas. As contagens das unidades formadoras de colônia (UFC $\mathrm{mL}^{-1}$ ) foram realizadas com auxílio de um contador de colônias.

O programa usado para as análises estatísticas foi o Assistat 7.5 Beta, utilizando-se as comparações entre as médias das amostras para análise de variância. Os dados foram submetidos à análise de variância com $5 \%$ de significância pelo Teste ' $F$ ' e quando significativo, usou-se o teste de Tukey a 5\%, para a comparação das médias dos tratamentos.

\section{RESULTADOS E DISCUSSÃO}

Nos solos rizosféricos das plantas, a quantidade de carbono orgânico, nitrogênio e a relação $\mathrm{C} / \mathrm{N}$ foram semelhantes aos encontrados por Luizão et al. (2004), Quesada et al. (2011) (Tabela 1). 
Tabela 1: Teores de carbono, nitrogênio, relação $\mathrm{C} / \mathrm{N}$ e matéria orgânica dos solos amostrados das rizosferas de plantas em épocas distintas de precipitação, na região de Urucu-Coari-AM.

\begin{tabular}{|c|c|c|c|c|c|}
\hline \multirow[t]{2}{*}{ Amostras } & \multirow[t]{2}{*}{ Época } & C & $\mathrm{N}$ & $\mathrm{C} / \mathrm{N}$ & M.O \\
\hline & & \multicolumn{4}{|c|}{------------g kg-1 de solo------------- } \\
\hline \multirow[t]{2}{*}{ Vismia guianensis } & chuva & 3,38 & 1,07 & 3,15 & 4,06 \\
\hline & seca & 3,30 & 0,95 & 3,47 & 5,68 \\
\hline \multirow[t]{2}{*}{ Mucuna pruriens } & chuva & 0,95 & 0,45 & 2,11 & 1,57 \\
\hline & seca & 0,78 & 0,34 & 2,29 & 1,35 \\
\hline \multirow[t]{2}{*}{ Brachiaria decumbens } & chuva & 1,24 & 0,55 & 2,25 & 2,32 \\
\hline & seca & 1,99 & 0,70 & 2,84 & 3,42 \\
\hline \multirow[t]{2}{*}{ Brachiaria humidicola } & chuva & 1,37 & 0,64 & 2,14 & 2,35 \\
\hline & seca & 3,64 & 0,21 & 17,3 & 5,26 \\
\hline
\end{tabular}

Os teores de $\mathrm{C}, \mathrm{N}$ e $\mathrm{MO}$ foram menores no solo rizosférico de Mucuna pruriens e os maiores, nos solos de Vismia guianensis, havendo uma interação na qual o solo da Brachiaria humidicola apresentou o menor teor de nitrogênio quando coletado na época seca, resultando por isso, na maior relação $\mathrm{C} / \mathrm{N}$ de todas as amostras analisadas, sendo também, a que apresentou a maior quantidade de matéria orgânica (MO). Os resultados apresentados a seguir são referentes às amostras de solos de plantas coletadas em duas épocas distintas, na província Petrolífera de Urucu.

Tabela 2: Características químicas dos solos rizosféricos de plantas dos solos amostrados das rizosferas de plantas em épocas distintas de precipitação, na região de Urucu-Coari-AM.

\begin{tabular}{|c|c|c|c|c|c|c|c|c|c|c|}
\hline \multirow[t]{2}{*}{ Amostras } & \multirow[t]{2}{*}{ Época } & $\mathrm{pH}\left(\mathrm{H}_{2} \mathrm{O}\right)$ & $\mathrm{Ca}++$ & $\mathrm{Mg}++$ & $\mathrm{Al}+++$ & $\mathrm{K}+$ & $\mathrm{P}$ & $\mathrm{Fe}$ & $\mathrm{Zn}$ & $\mathrm{Mn}$ \\
\hline & & \multicolumn{9}{|c|}{ 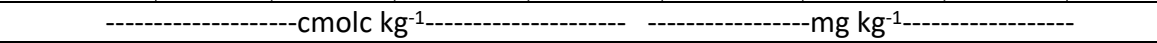 } \\
\hline \multirow[t]{2}{*}{ Vismia guianensis } & chuva & 4,4B & $0,5 \mathrm{M}$ & $0,18 \mathrm{~B}$ & $0,41 \mathrm{M}$ & $0,11 B$ & $0,01 B$ & $92,8 \mathrm{~A}$ & $1 \mathrm{~B}$ & $2,36 B$ \\
\hline & seca & $5,3 B$ & $2,3 \mathrm{~A}$ & $0,20 B$ & $0,13 B$ & $0,21 \mathrm{M}$ & $10,2 \mathrm{~A}$ & $333 A$ & $1,3 B$ & $1,9 \mathrm{~B}$ \\
\hline \multirow[t]{2}{*}{ Mucuna pruriens } & chuva & $6,8 \mathrm{M}$ & $1,2 \mathrm{M}$ & $0,11 \mathrm{~B}$ & $\mathrm{OB}$ & $0,15 B$ & $0,12 \mathrm{~B}$ & $103,4 \mathrm{~A}$ & $0,86 \mathrm{~B}$ & $3,84 \mathrm{~B}$ \\
\hline & seca & $7,5 \mathrm{M}$ & $4,2 \mathrm{~A}$ & $0,10 B$ & $\mathrm{OB}$ & $0,17 \mathrm{~B}$ & $109 \mathrm{~A}$ & $246 A$ & $1,9 B$ & $1,8 \mathrm{~B}$ \\
\hline \multirow[t]{2}{*}{ Brachiaria decumbens } & chuva & $7,4 \mathrm{M}$ & $0,5 \mathrm{M}$ & $0,14 \mathrm{~B}$ & $\mathrm{OB}$ & $0,27 \mathrm{M}$ & $0,3 \mathrm{M}$ & $145,4 \mathrm{~A}$ & $1,48 \mathrm{~B}$ & $3,74 B$ \\
\hline & seca & $6,5 \mathrm{M}$ & $5,9 \mathrm{~A}$ & $0,21 B$ & $\mathrm{OB}$ & $0,20 \mathrm{M}$ & $92 \mathrm{~A}$ & $188 \mathrm{~A}$ & $1,9 B$ & $2,6 \mathrm{~B}$ \\
\hline \multirow[t]{2}{*}{ Brachiaria humidicola } & chuva & $4,7 \mathrm{~B}$ & $0,6 \mathrm{M}$ & $0,13 B$ & $0,3 \mathrm{M}$ & $0,22 \mathrm{M}$ & $0,004 \mathrm{~B}$ & $101,6 \mathrm{~A}$ & $0,76 \mathrm{~B}$ & $2,48 B$ \\
\hline & seca & $6,9 \mathrm{M}$ & $5,2 \mathrm{~A}$ & $0,24 B$ & $\mathrm{OB}$ & $0,16 \mathrm{~B}$ & $12 \mathrm{~A}$ & $115 A$ & $1,8 \mathrm{~B}$ & $4,2 B$ \\
\hline
\end{tabular}

A classificação dos valores segundo Cochrane et al. (1985): $A$ = alto; $B$ = baixo; $M=$ médio; $S=$ satisfatório

Através dos dados foi possível perceber que houve aplicação de calagem nos solos rizosféricos ao redor do oleoduto para favorecer o crescimento dessas espécies (Tabela 2), uma vez que mais de $96 \%$ dos solos do Estado do Amazonas apresentam pH abaixo de 5,5 (MOREIRA et al., 2005). Com isso houve uma redução do alumínio e manganês tóxicos (MASCARENHAS et al., 1984; ESPER NETO et al., 2019), o que pode resultar em aumentos da absorção de nitrogênio, fósforo e potássio (QUAGGIO et al., 1993). O pH no período chuvoso dos solos rizosféricos de Mucuna pruriens e Brachiaria decumbens apresentaram acidez mediana e Vismia guianensis e Brachiaria humidicola são consideradas de baixo $\mathrm{pH}$, segundo os critérios de Cochrane et al. (1985). O pH no período seco dos solos rizosféricos de Mucuna pruriens e Brachiaria decumbens e Brachiaria humidicola apresentaram acidez mediana e Vismia guianensis é considerado baixo.

As concentrações de Al no período chuvoso foram consideradas médio em Vismia guianensis e Brachiaria humidicola e baixo em Mucuna pruriens e Brachiaria decumbens. Já no período seco as concentrações de Al foram consideradas baixas em todas as amostras de solo. As concentrações superiores a 1,5 $\mathrm{cmol} \mathrm{kg}{ }^{-1}$ de solo podem ser tóxicas para a maioria das plantas cultivadas. Os teores de $\mathrm{K}$ no período chuvoso nos solos rizosféricos de Vismia guianensis e Mucuna pruiens foram considerados baixos (<0,15 cmolc. de $\mathrm{K} \mathrm{kg}^{-1}$ de solo) e em Brachiaria decumbens e Brachiaria humidicola são considerados médio. Os 
teores de $\mathrm{K}$ no período seco nos solos rizosféricos de Mucuna pruiens e Brachiaria humidicola foram considerados baixos (<0,15 cmolc. de K kg-1 de solo), e em Vismia guianensis e Brachiaria decumbens são considerados médio. Os teores de $\mathrm{P}$ no solo no período seco foram superiores quando comparados ao período chuvoso. Quanto aos teores de micronutrientes encontrados nos solos rizosféricos nos dois períodos, observou-se alta variação para o Fe e pouca para o Zn e Mn. Os teores de Fe variaram de 92,8 a 145,4 mg kg-

${ }^{1}$ de solo no período chuvoso e 115 a $333 \mathrm{mg} \mathrm{kg}^{-1}$ de solo no período seco. Os teores de $\mathrm{Zn}$ e $\mathrm{Mn}$ são considerados baixos, segundo Cochrane et al. (1985).

\section{Enriquecimento das amostras}

As populações de bactérias das quatro espécies vegetais coletadas no período chuvoso cresceram até o 140 dia de incubação (Figura 1), independente da adição de petróleo ou não como fonte de carbono. No entanto, a adição do petróleo resultou em maior crescimento nos tratamentos contendo solos rizosféricos de Vismia (Fig. 1a), Mucuna (Fig. 1b) e B. humidicola (Fig. 1d), indicando que essas bactérias usaram tanto as fontes de carbono presentes no solo como o próprio petróleo para crescerem. Esse comportamento só foi diferente com a população de bactérias presente na rizosfera de $B$. decumbens (Fig. 1c), que cresceu de forma significativamente semelhante, independente da adição ou não do petróleo durante o período de incubação. É possível, nesse caso, que a maioria da população de bactérias presentes na rizosfera dessa gramínea esteja totalmente adaptada para consumir o petróleo colocado nas placas de Petri, independentemente de estar ou não incubada previamente com esse componente orgânico.

Já as populações presentes nas rizosferas das outras espécies, pelo menos em parte, ainda não estavam adaptadas ao petróleo. Ao serem adicionadas nas placas de Petri contendo o petróleo como fonte de carbono, apenas aquela parte da população dos frascos testemunhas, capaz de usar o petróleo, cresceu no meio com sua adição, sendo, portanto, menor do que as dos frascos incubados com esse componente orgânico, que foi usado pela parte da população adaptada, que por isso, apresentou maior população até o 14으 dia de incubação. Ao se analisar as escalas de valores nos eixos $Y$ da Figura 1, percebe-se que a população de bactérias capazes de usar o petróleo foi bem menor na rizosfera do lacre (Vismia guianensis), que não chegou a atingir cerca de $2500 \times 10^{5} \mathrm{UFC} \mathrm{g}^{-1}$ Solo, enquanto que as das outras espécies de plantas adicionadas previamente com petróleo ultrapassaram $3500 \times 10^{5} \mathrm{UFC} \mathrm{g}^{-1}$ solo e chegando, como no caso da B. humidicola, a $4000 \times 10^{5}$ UFC g $^{-1}$ solo.

A menor população de bactérias capazes de usar o petróleo no solo rizosférico da Vismia pode ser devido ao sistema radicular muito pouco desenvolvido pelas mudas coletadas no campo (menores do que 1 $\mathrm{m}$ de altura), com produções muito baixas de exsudatos radiculares capazes de manter altas populações de microrganismos rizosféricos. Observou-se que as bactérias levam algum tempo para se adaptarem à nova fonte de carbono (meio enriquecido), seguindo-se um aumento significativo desses microrganismos e de mineralização do petróleo. Foi detectada ainda uma queda significativa das populações de bactérias capazes de quebrar o petróleo aos 21 dias de incubação, sugerindo que exauriram a maior parte das fontes de carbono presentes nos solos, pressupondo-se assim, que os componentes do petróleo adicionado como 
contaminante tenha sido total ou quase totalmente convertidos em $\mathrm{CO}_{2}$ e água por essas bactérias nesse período.

No 28으 dia esse decaimento continuou em Brachiaria decumbens (c) e Brachiaria humidicola (d), porém em Vismia guianensis (a) e Mucuna pruriens (b) ocorreu um pequeno aumento, sugerindo que estavam usando as fontes de carbono presentes no solo (M.O. e petróleo) de forma diferenciada das demais. Esse processo de exaurimento das fontes de carbono presentes nos solos deve ter sido completado aos 35 dias de incubação, quando as populações presentes nas amostras de solos se estabilizaram com valores próximos ao zero.

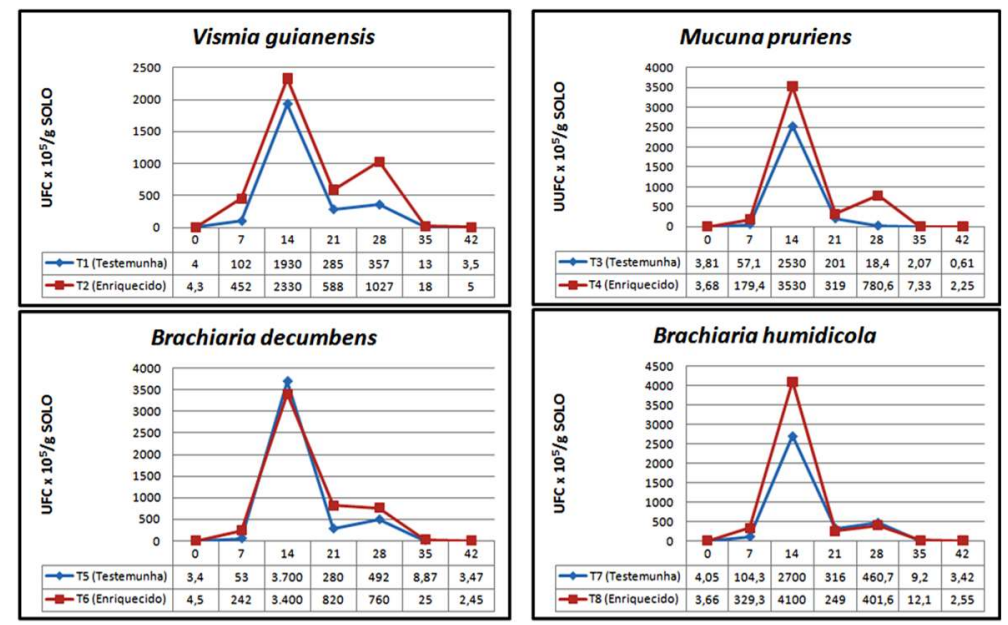

Figura 1: Populações de bactérias coletadas no período chuvoso, em meio enriquecido previamente ou não com petróleo a) Vismia guianensis; b) Mucuna pruriens; c) Brachiaria decumbens; d) Brachiaria humidicola.

Ao se analisar as populações rizosféricas de bactérias coletadas no período seco (Figura 2), observase que todas as quatro espécies de plantas apresentaram também, maiores crescimentos aos 14 dias de incubação, mas nesse caso, houve uma pequena mudança de comportamento em relação à coleta do período chuvoso. A pré-incubação com petróleo permitiu maiores populações de bactérias em todos os tratamentos quando comparados com suas testemunhas sem a adição prévia desse contaminante, sendo que as maiores diferenças foram observadas pelas populações das braquiárias (Figura 2 c, d). Esses resultados mostram que a adição do petróleo estimulou o crescimento bacteriano presente nas rizosferas dessas espécies.

Observou-se uma queda significativa das populações de bactérias capazes de quebrar o petróleo aos 21 dias de incubação, sugerindo que esgotaram a maior parte das fontes de carbono presentes nos solos, implicando-se assim, que o petróleo adicionado como contaminante tenha sido total ou quase totalmente convertido em $\mathrm{CO}_{2}$ e água por essas bactérias nesse período. No 28 o dia esse decaimento continuou em Brachiaria decumbens (c), porém em Vismia guianensis (a), Mucuna pruriens (b) e Brachiaria humidicola (d), ocorreu um pequeno aumento, sugerindo que estavam usando as fontes de carbono presentes no solo (M.O. e petróleo) de forma diferenciada das demais. Esse processo de exaurimento das fontes de carbono presentes nos solos deve ter sido completado aos 35 dias de incubação, quando as populações presentes nas amostras de solos se estabilizaram com valores próximos ao zero. 

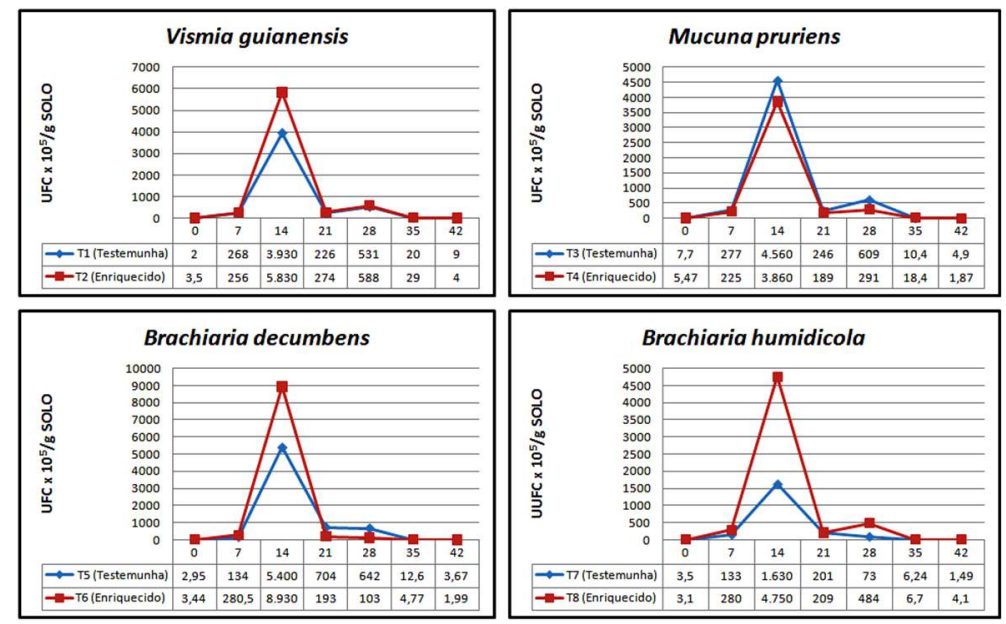

Figura 2: Populações de bactérias coletadas no período seco, em meio enriquecido previamente ou não com petróleo.

a) Vismia guianensis; b) Mucuna pruriens; c) Brachiaria decumbens; d) Brachiaria humidicola.

As populações de fungos filamentosos presentes nas rizosferas das quatro espécies vegetais coletadas no período chuvoso cresceram até o 14 dia de incubação (Figura 3) no tratamento testemunha de Vismia guianensis (Fig. 3a) e Brachiaria decumbens (Fig. 3c) e, nos tratamentos enriquecidos de Mucuna pruriens (Fig. 3b) e Brachiaria humidicola (Fig. 3d). Já no tratamento com adição de petróleo de Vismia guianensis (Fig. 3a) e B. decumbens (Fig. 3c), as populações de fungos filamentosos cresceram até o 21 으 dia de incubação. A adição do petróleo resultou em maior crescimento fúngico nos tratamentos contendo solos rizosféricos de Vismia (Fig. 3a) e Mucuna (Fig. 3b), indicando que esses fungos filamentosos usaram tanto as fontes de carbono presentes no solo como o próprio petróleo para crescerem. Esse comportamento só foi diferente com a população de fungos filamentosos presentes na rizosfera de B. humidicola (Fig. 3d), que cresceu de forma semelhante, independente da adição ou não do petróleo durante o período de incubação e, em B. decumbens (Fig. 3c), onde a população de fungos filamentosos presente na rizosfera no tratamento sem a adição do petróleo resultou em maior crescimento do que no tratamento enriquecido.

É possível que a maioria da população de fungos filamentosos na rizosfera de $B$. humidicola e de $B$. decumbens esteja totalmente adaptada para consumir o petróleo colocado nas placas de Petri, independentemente de estar ou não incubada com esse componente orgânico. Já as populações presentes nas rizosferas das outras espécies, pelo menos em parte, ainda não estavam adaptadas ao petróleo. Ao serem adicionadas nas placas de Petri contendo o petróleo como fonte de carbono, apenas aquela parte da população dos frascos testemunhas, capaz de usar o petróleo, cresceu no meio com sua adição, sendo, portanto, menor do que as dos frascos incubados com esse componente orgânico, que foi usado pela parte da população adaptada.

Ao se analisar as escalas de valores nos eixos $Y$, percebe-se que a população de fungos filamentosos capazes de usar o petróleo foi bem menor na rizosfera de B. humidicola (Fig. 3d), que chegou a atingir um máximo de $100 \times 10^{5} \mathrm{UFC} \mathrm{g}{ }^{-1}$ solo. Em seguida se encontram as populações observadas no solo rizosférico de Vismia (Fig. 3a), que atingiram os máximos de $200 \times 10^{5} \mathrm{UFC}^{-1}$ solo no tratamento testemunha e $330 \times 10^{5}$ UFC $\mathrm{g}^{-1}$ solo no tratamento previamente enriquecido com o petróleo. No caso dos fungos da rizosfera de $M$.

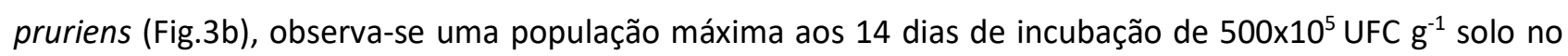


tratamento previamente enriquecido com petróleo, mas uma que se manteve próxima ao zero no tratamento testemunha, fato esse único em todo o experimento. No caso da população de fungos encontrados na rizosfera de $B$. decumbens (Fig. 3c), houve uma inversão de valores, no qual o petróleo, ao ser adicionado previamente no solo antes da incubação, retardou o crescimento dos fungos e o seu máximo atingindo cerca de $360 \times 10^{5}$ UFC g ${ }^{-1}$ solo aos 21 dias de incubação, sendo inferior ao máximo observado no tratamento testemunha, de aproximadamente $500 \times 10^{5} \mathrm{UFC} \mathrm{g}^{-1}$ solo aos 14 dias de incubação.

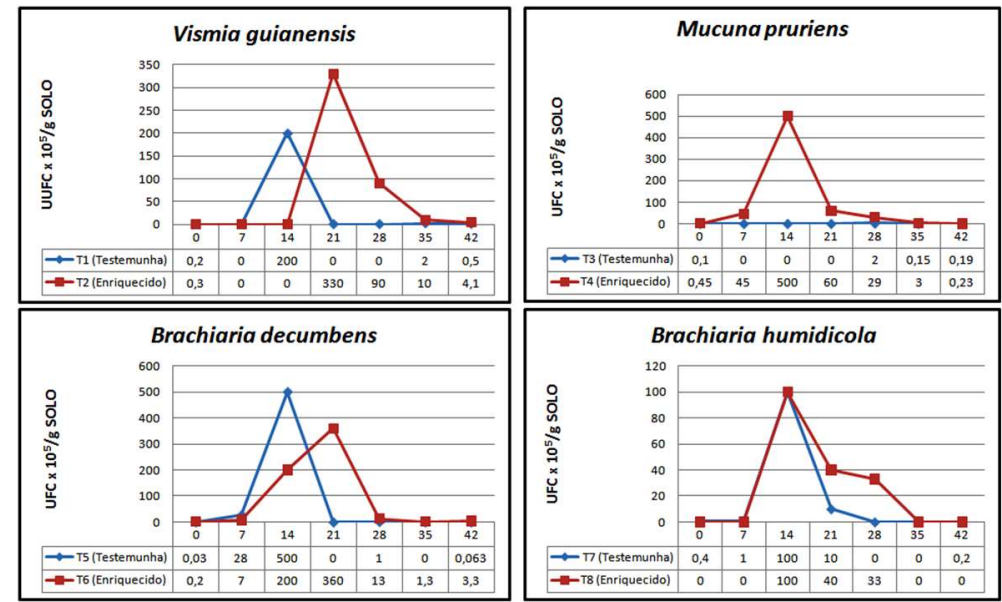

Figura 3: Populações de fungos filamentosos coletadas no período chuvoso, em meio enriquecido previamente ou não com petróleo a) Vismia guianensis; b) Mucuna pruriens; c) Brachiaria decumbens; d) Brachiaria humidicola.

A menor população de fungos filamentosos capazes de usar o petróleo no solo rizosférico de $B$. humidicola possivelmente deve-se à baixa competição dos fungos filamentosos com os microrganismos (bactérias e leveduras). De acordo com Cunha et al. (2000) o crescimento de uma população específica causa um desequilíbrio na comunidade por competição por espaços físicos, nutrientes e água, reduzindo para pequenas quantidades, os microrganismos que têm o melhor desempenho na biodegradação. Observou-se uma queda significativa das populações de fungos filamentosos capazes de quebrar o petróleo aos 21 dias de incubação em M. pruriens (Fig. 3b) e B. humidicola (Fig. 3d), sugerindo que exauriram as fontes de carbono presentes nos solos, pressupondo-se assim, que o petróleo adicionado como contaminante tenha sido total ou quase totalmente convertido em $\mathrm{CO}_{2}$ e água por esses fungos filamentosos nesse período. $\mathrm{Em} V$. guianensis (Fig. 3a) e B. decumbens (Fig. 3c) ocorreu uma queda significativa das populações de fungos filamentosos capazes de quebrar o petróleo somente no $28^{\circ}$ dia. Além disso, observou-se que em $M$. pruriens (b) e B. humidicola (d) continuaram decaindo. No 35 o dia esse decaimento continuou em V. guianensis (a) e B. decumbens (c); já em M. pruriens (b) e B. humidicola (d) esse processo de exaurimento das fontes de carbono presentes nos solos deve ter sido completado, quando as populações presentes nas amostras de solos se estabilizaram com valores próximos ao zero.

$O$ processo de exaurimento das fontes de carbono presentes nos solos ocorreu em $V$. guianensis (a) e B. decumbens (c) aos 42 dias de incubação, quando foram observados os valores próximos ao zero, indicando que as populações presentes nas amostras de solos se estabilizaram. Ao se analisar as populações rizosféricas de fungos filamentosos coletadas no período seco (Figura 18), observou-se que a maioria das espécies de plantas apresentou também, maiores crescimentos aos 14 dias de incubação, com exceção de 
Brachiaria decumbens no tratamento testemunha, que cresceu até o 210 dia de incubação. Pode-se observar que ocorreu uma pequena mudança de comportamento em relação à coleta do período chuvoso. As populações de fungos filamentosos nos tratamentos com e sem petróleo permitiu maiores populações quando comparados com o período chuvoso, sendo que as maiores diferenças foram observadas pelas populações de fungos encontrados nas rizosferas de Vismia guianensis, Mucuna pruriens e Brachiaria decumbens (Figura 4a, b, c). A pré-incubação com petróleo permitiu maiores populações de fungos filamentosos somente em Mucuna pruriens quando comparado com a sua respectiva testemunha (Figura 4b). Esses resultados mostram que a adição do petróleo estimulou o crescimento fúngico presente na rizosfera dessa espécie.
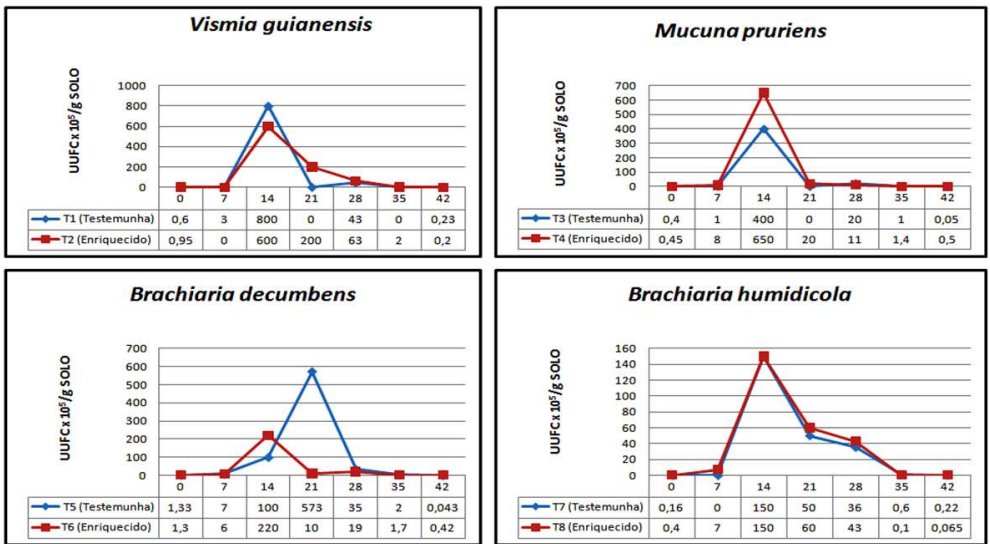

Figura 4: Populações de fungos filamentosos coletadas no período seco, em meio enriquecido previamente ou não com petróleo a) Vismia guianensis; b) Mucuna pruriens; c) Brachiaria decumbens; d) Brachiaria humidicola.

Observou-se uma queda significativa das populações de fungos capazes de quebrar o petróleo aos 21 dias de incubação (exceto na amostra contendo solo rizosférico de B. humidicola), sugerindo que exauriram as fontes de carbono presentes nos solos, pressupondo-se assim, que o petróleo adicionado como contaminante tenha sido total ou quase totalmente convertido em $\mathrm{CO}_{2}$ e água por esses fungos nesse período. Esse processo de exaurimento das fontes de carbono presentes nos solos deve ter sido completado aos 35 dias de incubação, quando as populações presentes nas amostras de solos se estabilizaram com valores próximos ao zero.

As populações de leveduras (fungos unicelulares) presentes nas rizosferas das quatro espécies vegetais coletadas no período chuvoso cresceram até o 14ㅇdia de incubação (Figura 5), independente da adição de petróleo ou não como fonte de carbono. No entanto, a adição do petróleo resultou em maior crescimento nos tratamentos contendo solos rizosféricos de $M$. pruriens (Fig. 5b) e B. decumbens (Fig. 5c), indicando que essas leveduras usaram tanto as fontes de carbono presentes no solo como o próprio petróleo para crescerem. Esse comportamento foi diferente com a população de leveduras presente na rizosfera de V. guianensis (Fig. 5a) e na população de B. humidicola (Fig. $5 \mathrm{~d}$ ), que cresceu de forma significativamente semelhante, independente da adição ou não do petróleo durante o período de incubação. É possível, nesse caso, que a maioria da população de leveduras presentes na rizosfera dessa gramínea esteja totalmente adaptada para consumir o petróleo colocado nas placas de Petri, independentemente de estar ou não incubada com esse componente orgânico. Já as populações presentes nas rizosferas das outras espécies, pelo 
menos em parte, ainda não estavam adaptadas ao petróleo. Ao serem adicionadas nas placas de Petri contendo o petróleo como fonte de carbono, apenas aquela parte da população dos frascos testemunhas, capaz de usar o petróleo, cresceu no meio com sua adição, sendo, portanto, menor do que as dos frascos incubados com esse componente orgânico, que foi usado pela parte da população adaptada, que por isso, apresentou maior população até o 14을 dia de incubação.
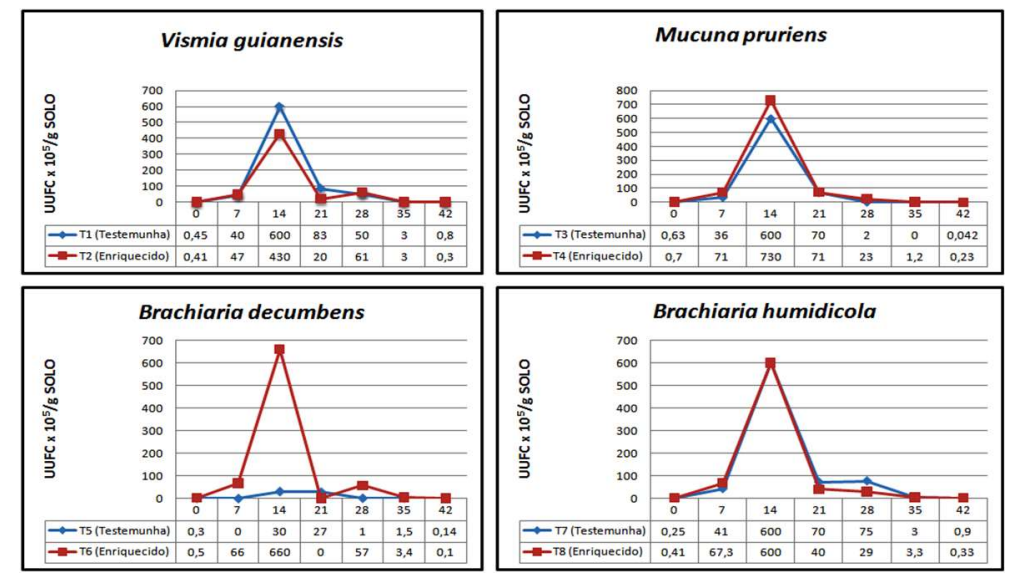

Figura 5: Populações de leveduras (fungos unicelulares) coletadas no período chuvoso, em meio enriquecido previamente ou não com petróleo a) Vismia guianensis; b) Mucuna pruriens; c) Brachiaria decumbens; d) Brachiaria humidicola.

Ao se analisar as escalas de valores nos eixos y, percebe-se que a população de leveduras capazes de

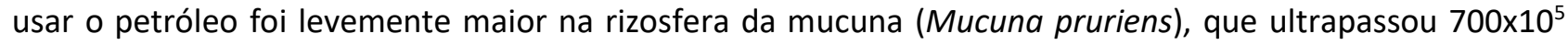
UFC g ${ }^{-1}$ solo, seguida pela da $B$. decumbens, com aproximadamente $650 \times 10^{5} \mathrm{UFC} \mathrm{g}^{-1}$ solo e chegando, como no caso da M. pruriens, a $7300 \times 10^{5} \mathrm{UFC} / \mathrm{g}$ Solo. A menor população de leveduras capazes de usar o petróleo no solo rizosférico da Vismia pode ser devido ao sistema radicular muito pouco desenvolvido pelas mudas coletadas no campo (menores do que $1 \mathrm{~m}$ de altura), com produções muito baixas de exsudatos radiculares capazes de manter altas populações de microrganismos rizosféricos. Observou-se uma queda significativa das populações de leveduras capazes de quebrar o petróleo aos 21 dias de incubação, sugerindo que exauriram as fontes de carbono presentes nos solos, pressupondo-se assim, que o petróleo adicionado como contaminante tenha sido total ou quase totalmente convertido em $\mathrm{CO}_{2}$ e água por essas leveduras nesse período. No 28 dia esse decaimento continuou em Mucuna pruriens (b) e Brachiaria humidicola (d), porém em Vismia guianensis (a) e Brachiaria decumbens (c) ocorreu um pequeno aumento, sugerindo que estavam usando as fontes de carbono presentes no solo (M.O. e petróleo) de forma diferenciada das demais. Esse processo de exaurimento das fontes de carbono presentes nos solos deve ter sido completado aos 35 dias de incubação, quando as populações presentes nas amostras de solos se estabilizaram com valores próximos ao zero.

Ao se analisar as populações rizosféricas de leveduras coletadas no período seco (Figura 6), observase que todas as quatro espécies de plantas apresentaram também, maiores crescimentos aos 14 dias de incubação, mas nesse caso, houve uma pequena mudança de comportamento em relação à coleta do período chuvoso. A pré-incubação com petróleo permitiu maiores populações de leveduras em $V$. guianensis (Fig. 6a), M. pruriens (Fig. 6b) e B. decumbens (Fig. 6c) quando comparados com suas testemunhas sem a adição 
prévia desse contaminante, sendo que a maior diferença foi observada pela população de $B$. decumbens (Fig. 6c). Esses resultados mostram que a adição do petróleo estimulou o crescimento de leveduras presentes nas rizosferas dessas espécies.

Ao se analisar as escalas de valores nos eixos $Y$, percebe-se que a população de leveduras capazes de usar o petróleo foi bem menor na rizosfera de $B$. humidicola, que atingiu $700 \times 10^{5} \mathrm{UFC} \mathrm{g}^{-1}$ solo, enquanto que as das outras espécies de plantas adicionadas previamente com petróleo ultrapassaram $1000 \times 10^{5} \mathrm{UFC} / \mathrm{g}$ Solo e chegando, como no caso da B. decumbens, a $1730 \times 10^{5} \mathrm{UFC} \mathrm{g}^{-1}$ solo.

Observou-se uma queda significativa das populações de leveduras capazes de quebrar o petróleo aos 21 dias de incubação, sugerindo que esgotaram as fontes de carbono presentes nos solos, implicando-se assim, que o petróleo adicionado como contaminante tenha sido total ou quase totalmente convertido em $\mathrm{CO}_{2}$ e água por essas bactérias nesse período. № 28 dia esse decaimento continuou em Mucuna pruriens (b) e Brachiaria decumbens (c), porém em Vismia guianensis (a) e Brachiaria humidicola (d), ocorreu um pequeno aumento, sugerindo que estavam usando as fontes de carbono presentes no solo (M.O. e petróleo) de forma diferenciada das demais. Esse processo de exaurimento das fontes de carbono presentes nos solos deve ter sido completado aos 35 dias de incubação, quando as populações presentes nas amostras de solos se estabilizaram com valores próximos ao zero.
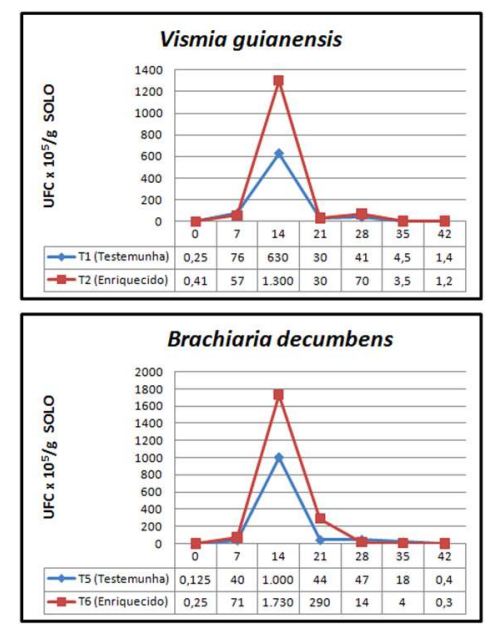
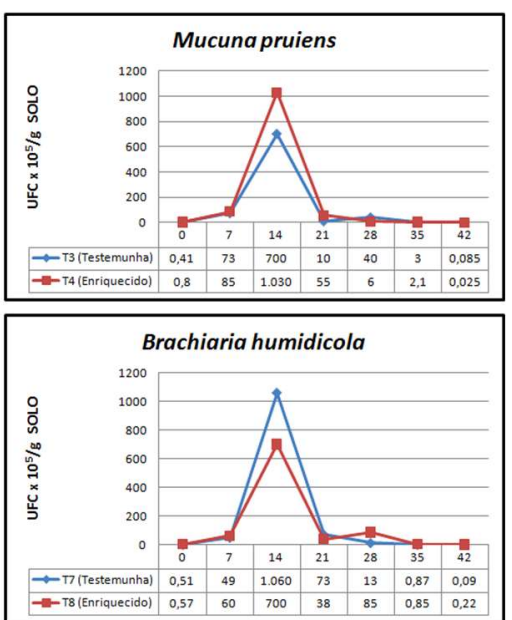

Figura 6: Populações de leveduras coletadas no período seco, em meio enriquecido previamente ou não com petróleo a) Vismia guianensis; b) Mucuna pruriens; c) Brachiaria decumbens; d) Brachiaria humidicola.

A população predominante nos solos analisados foi a de bactérias, o que está de acordo com o encontrado em diversos trabalhos que afirmam que as bactérias são os organismos mais abundantes na rizosfera de plantas (BECKER et al., 1988; CHANWAY et al., 1991; JACOBY et al., 2017). A habilidade de degradação do petróleo é apresentada por diversos microrganismos, principalmente bactérias e fungos filamentosos, embora a ubiquidade deles nos ecossistemas terrestres. Morgan et al. (1994) afirmam que além das bactérias e fungos filamentosos, existem vários gêneros de leveduras e algas unicelulares que possuem capacidade de metabolizar hidrocarbonetos de petróleo. Dessa forma, o conhecimento da diversidade da comunidade rizosférica poderá ajudar nos processos de biorremediação de maneira a estimular e acelerar a biodegradação dos ambientes que podem ser impactados com petróleo. 


\section{CONCLUSÕES}

A adição de petróleo ao meio de cultura resultou em aumentos significativos de microrganismos

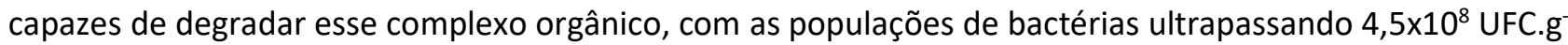
${ }^{1}$ de solo, fungos filamentosos ultrapassando $1,4 \times 10^{7}$ UFC $\mathrm{g}^{-1}$ de solo e leveduras ultrapassando $6,0 \times 10^{7} \mathrm{UFC} . \mathrm{g}$ ${ }^{1}$ de solo, populações essas, capazes de contribuir para a degradação do petróleo caso ocorra algum derramamento ao longo do oleoduto. Entre as quatro espécies, a Brachiaria decumbens apresentou a maior ocorrência de microrganismos degradadores de petróleo. As maiores concentrações de UFC (Unidades Formadoras de Colônias) de bactérias, fungos filamentosos e leveduras ocorreram no período seco. No período chuvoso, a maior concentração de UFC de bactérias ocorreu em Brachiaria humidicola e, de fungos filamentosos e leveduras em Mucuna prurinens. No período seco, a maior concentração de UFC de bactérias ocorreu em Brachiaria decumbens, de fungos filamentosos em Mucuna pruriens e leveduras em Brachiaria decumbens.

AGRADECIMENTOS: Ao Conselho Científico de Desenvolvimento Científico e Tecnológico (CNPq), Petróleo Brasileiro S.A. (PETROBRAS) e Financiadora de Estudos e Projetos (FINEP) pelo apoio financeiro para a realização dessa pesquisa.

\section{REFERÊNCIAS}

ANDERSON, J. M.; INGRAM, J. S. I.. Tropical soil biological and fertility: a handbook of methods. 2 ed. Wallingford: $C A B$ International, 1993.

ATLAS, R. M.. Petroleum Biodegradation and oil spill Bioremediation. Marine Pollution Bull., v.31, p.178-182, 1995.

BECKER, J. O.; ZAVALETA-MEJIA, E.; COLBERT, S. F.; SCHROTH, M. N.; WEINHOLD, A. R.; HANCOCK, J. G.; VAN GUNDY, S. D.. Effect of rhizobacteria on root-knot nematodes and gall formation. Phytopathology, v.78, p.1466-1469, 1988.

CHANWAY, C. P.; TURKINGTON, R.; HOLL, F. B.. Ecological implications of specificity between plants and rhizosphere microorganisms. Advances in Ecological Research, v.21, p.121-169, 1991.

COCHRANE, T. T.; SÁNCHEZ, L. G.; AZEVEDO, L. G.; PORRAS, J. A.; GARVER, C. L.. Land in Tropical America. 1985.

CUNHA, D. C.; LEITE, S. G. F.. Gasoline Biodegradation in Different Soil Microcosms. Brazilian Journal of Microbiology, São Paulo, v.31, n.1, 2000. DOI: http://doi.org/10.1590/S1517-83822000000100011

EMBRAPA. Empresa Brasileira de Pesquisa Agropecuária. Manual de Análises Químicas de Solos, Plantas e Fertilizantes. 2 ed. Brasília: EMBRAPA, 2009.

ESPER NETO, M.; CONEGLIAN, C. F.; COSTA, A. C. S.; INOUE, T. T.; BATISTA, M. A.. Short-term effects of liming on chemical attributes of tropical sandy soil and soybean
(Glycine max L.) yield. Australian Journal of Crop Science, v.13, n.6, p.889-894, 2019.

JACOBY, R.; PEUKERT, M.; SUCCURRO, A.; KOPRIVOVA, A.; KOPRIVA, S.. The role of soil microorganisms in plant mineral nutrition: Current knowledge and future directions. Front Plant Sci., v.8, p.18, 2017.

DOI: http://doi.org/10.3389/fpls.2017.01617

LUIZÃO, R. C. C.; LUIZÃO, F. J.; PAIVA, R. Q.; MONTEIRO, T. F.; SOUZA, L. S.; KRUIJT, B.. Variation of carbon and nitrogen cycling processes along a topographic gradient in a Central Amazonian forest. Global Change Biol., v.22, p.592-600, 2004.

MASCARENHAS, H. A. A.; CAMARGO, C. E. O.; FALIVENE, S. M. P.. Efeito do alumínio sobre o crescimento de raízes, peso seco da parte aérea e raízes de diferentes de cultivares de soja. Bragantia, Campinas, v.43, n.1, p.191-200, 1984.

MOREIRA, A.; GONÇALVES, J. R. P.; PLÁCIDO JÚNIOR, C. G. Mapa da distribuição aproximada da fertilidade dos solos do Estado do Amazonas. Manaus: Embrapa Amazônia Ocidental, 2005.

MORGAN, P.; WATKINSON, R. J.. Biodegradation of components of petroleum. In: RATLEDGE, C.. Biochemistry of Microbial Degradation. London: Kluwe Academic, 1994.

MURATOVA, A.; DMITRIEVA, T.; PANCHENKO, L.; TURKOVSKAYA, O.. Phytoremediation of oil-sludgecontaminated soil. International Journal of Phytoremediation, v.10, p.485-502, 2008. DOI: http://doi.org/10.1080/15226510802114920 
QUAGGIO, J. A.; VAN RAIJ, B.; GALLO, P. B.; MASCARENHAS, H. A. A.. Respostas da soja à aplicação de calcário e gesso e lixiviação de íons no perfil do solo. Pesquisa Agropecuária Brasileira, Brasília, v.28, n.3, p.375-383, 1993.

QUESADA, C. A.; LLOYD, J.; ANDERSON, L. O.; FYLLAS, N. M.; SCHWARZ, M.; CZIMCZIK, C. I.. Soils of Amazonia with particular reference to the RAINFOR sites, Biogeosciences, v.8, p.1415-1440, 2011. DOI: http://doi.org/10.5194/bg-8$\underline{1415-2011}$

VIEIRA, L. S.; SANTOS, P. C. T.. Amazônia: seus solos e outros recursos naturais. São Paulo: Agronômica Ceres, 1987.

A CBPC - Companhia Brasileira de Produção Científica (CNPJ: 11.221.422/0001-03) detém os direitos materiais desta publicação. Os direitos referem-se à publicação do trabalho em qualquer parte do mundo, incluindo os direitos às renovações, expansões e disseminações da contribuição, bem como outros direitos subsidiários. Todos os trabalhos publicados eletronicamente poderão posteriormente ser publicados em coletâneas impressas sob coordenação da Sustenere Publishing, da Companhia Brasileira de Produção Científica e seus parceiros autorizados. Os (as) autores (as) preservam os direitos autorais, mas não têm permissão para a publicação da contribuição em outro meio, impresso ou digital, em português ou em tradução. 